\title{
Use of machine-learning algorithms for the automated detection of cold-water coral habitats: a pilot study
}

\author{
Autun Purser ${ }^{1, *}$, Melanie Bergmann ${ }^{2}$, Tomas Lundälv ${ }^{3}, J_{o ̈ r g}$ Ontrup ${ }^{4}$, \\ Tim W. Nattkemper ${ }^{4}$ \\ ${ }^{1}$ Jacobs University, Campus Ring 1, 28759 Bremen, Germany \\ ${ }^{2}$ Alfred Wegener Institute for Polar and Marine Research, Am Handelshafen 12, 27570 Bremerhaven, Germany \\ ${ }^{3}$ Sven Lovén Centre for Marine Sciences, University of Gothenburg, Tjärnö, 45296 Strömstad, Sweden \\ ${ }^{4}$ Bielefeld University, Faculty of Technology, Biodata Mining \& Applied Neuroinformatics Group, PO Box 100131, \\ 33501 Bielefeld, Germany
}

\begin{abstract}
Cold-water coral reefs are recognised as important biodiversity hotspots on the continental margin. The location of terrain features likely to be associated with living reef has been made easier by recent developments in acoustic sensing technology. For accurate assessment and finescale mapping of these newly identified coral habitats, analysis of video data is still required. In the present study we explore the potential of manual and automatic abundance estimation of cold-water corals and sponges from still image frames extracted from video footage from Tisler Reef (Skagerrak, Norway). The results and processing times from 3 standard visual assessment methods (15-point quadrat, 100-point quadrat and frame mapping) are compared with those produced by a new computer vision system. This system uses machine-learning algorithms to detect species within frames automatically. Cold-water coral density estimates obtained from the automated method were similar to those gained by the other methods. The automated method slightly underestimated (by 10 to $20 \%$ ) coral coverage in frames which lacked a uniform seabed illumination. However, it did much better in the detection of small live coral fragments than the 15-point method. For assessing sponge coverage, the automated system did not perform as satisfactorily. It mistook a percentage of the seabed for sponge $(0.1$ to $2 \%$ of most frames) and underestimated sponge coverage in frames that contained many sponges. Results indicate that the machine-learning approach is appropriate for estimating live cold-water coral density, but further work is required before the system can be applied to sponges within the reef environment.
\end{abstract}

KEY WORDS: Machine-learning · Image analysis · ROV · Lophelia pertusa · Geodia baretti Mycale lingua $\cdot$ Cold-water coral $\cdot$ MPA

Resale or republication not permitted without written consent of the publishe

\section{INTRODUCTION}

There are a number of standard methodologies used to assess community structure from benthic video and still images. Assessments tend to quantify either numbers of individuals or the percentage of seabed covered by either a particular substrate or species within an image or video still (Jaap \& McField 2001). How this is carried out varies with methodology. Perhaps the most commonly used method is the point quadrat method (Pielou 1974). This method entails overlaying the image or still with an array of points (number of points variable; increasing the number of points increases both accuracy and assessment effort) and quantifying the number of points intersecting with the various species and/or substrates within the image. Another approach is to map all the species and substrates present in an image onto a video or digital overlay and determine from this the percentage coverage of each organism or substrate (Andrew \& Mapstone 
1987). Although the assessment effort is much higher with this second method, accuracy is greatly improved (Foster et al. 1991, Whorff \& Griffing 1992).

Accuracy and efficiency of these methods has been investigated in a selection of ecosystems, such as tropical coral reefs (Leujak \& Ormond 2007). Their usefulness in some environments, such as within cold-water coral ecosystems, has not been rigorously assessed. In this pilot study, we compare the ability of these 2 methods to assess some aspects of cold-water coral community structure at Tisler Reef, Norway. Additionally these results are compared with those produced by a wholly new approach: the use of machine-learning algorithms in the automated identification and quantification of cold-water coral and sponge coverage within still images extracted from video footage.

Cold-water coral ecosystems have been found throughout the world's oceans (Roberts et al. 2006). In European waters, they are often associated with coldwater carbonate mounds, ridges at the edge of the continental shelf or at other elevated structures such as banks and sills (White et al. 2005, Dorschel et al. 2007). Key organisms in these ecosystems are the frameworkbuilding scleractinian corals (Roberts et al. 2006). These non-zooxanthellate animals form complex 3dimensional reef structures as they excrete hard calcium carbonate skeletons during growth (Rogers 1999, Hovland 2008). As a reef develops over time, this structure can attain significant height above the surrounding seabed (De Mol et al. 2007) despite the slow growth rates of the corals themselves (Gass \& Roberts 2006, Orejas et al. 2008). In Europe, Lophelia pertusa is the most significant reef-building coral species (Wheeler et al. 2007), although Madrepora oculata can also be found performing this role at certain locations, often in close association with $L$. pertusa (Mortensen et al. 2008). The reef structures are characterized by high biodiversity (Jonsson et al. 2004, Roberts et al. 2008), as the dead skeletal material of the reef provides a useful substrate for sessile filter feeders such as sponges (Henry \& Roberts 2007). Furthermore, the increased flow associated with elevation from the seabed increases food supply (Thiem et al. 2006, Kiriakoulakis et al. 2007). Many species of small and juvenile fish use these reef structures as nursery habitat, as they provide shelter from predation (Reed 2002). Commercial fish densities within the reef environment are often higher than in the surrounding ocean (Husebø et al. 2002, Costello et al. 2005). Although cold-water corals have been known since the 18th century (Roberts et al. 2003), the extent of seabed covered by these organisms and associated ecosystems, as well as their potential importance to commercial fisheries, only emerged in the late 20th century (Costello et al. 2005). Advances in marine sampling technology indicate that these ecosystems are relatively common in European waters, and many reefs have been located in recent years (Roberts et al. 2005, Wienberg et al. 2008). Unfortunately, these discoveries are rarely of pristine reefs. The majority show signs of impacts from towed fishing gears (Fosså et al. 2002). Common indicators of such impacts are dislodged blocks of live coral, snagged and abandoned fishing equipment and extended areas of broken coral fragments amongst trawl tracks. Various legal attempts to protect a percentage of these reefs against further damage have been made by a number of nations (Armstrong \& van den Hove 2008) with variable success (Davies et al. 2007).

Monitoring of cold-water coral reefs requires methods for the spatial assessment of community structure. This is more challenging than for tropical coral reefs, with the majority of European cold-water corals found at depths beyond the reach of SCUBA diving (Wisshak et al. 2005). Although acoustic methods are improving rapidly and have increased success in locating areas of cold-water coral at large scales (Fosså et al. 2005), analysis of box cores and video or still image data collected by remotely operated vehicle (ROV), submarine or video sled remains the main approach for resolving community structure variance across individual reefs (Henry \& Roberts 2007, Mortensen et al. 2008).

Tisler Reef was first documented by ROV in 2002 (Lavaleye et al. 2009). The primary spatial contributors within the reef community are the coral Lophelia pertusa and the sponges Geodia baretti and Mycale lingua. As has been found elsewhere in European waters, mapping has revealed that large parts of the reef have been damaged by towed fishing gears (Lundälv \& Jonsson 2003, Jonsson 2006). In December 2003, trawling was banned and a video transect established to study the recovery of the reef. Inevitably, such monitoring schemes produce large quantities of image data, especially when repeated over time.

The objective of this pilot study was to quantify the coverage of the seafloor by cold-water corals and sponges on images taken by ROV at Tisler Reef. The accuracy and processing time of 3 manual and a new automated method in estimating coral and sponge coverage was compared. The ultimate goal was to develop new methods to expedite the currently lengthy process of manual image analysis. In the present study the focus was solely on coral and sponge coverage estimation, with the densities of other fauna and/or reef biodiversity not assessed.

\section{MATERIALS AND METHODS}

Study site. Video transect data was collected from Tisler Reef by ROV (Fig. 1). The reef is located on a sill in the Norwegian Skagerrak, close to the Swedish bor- 


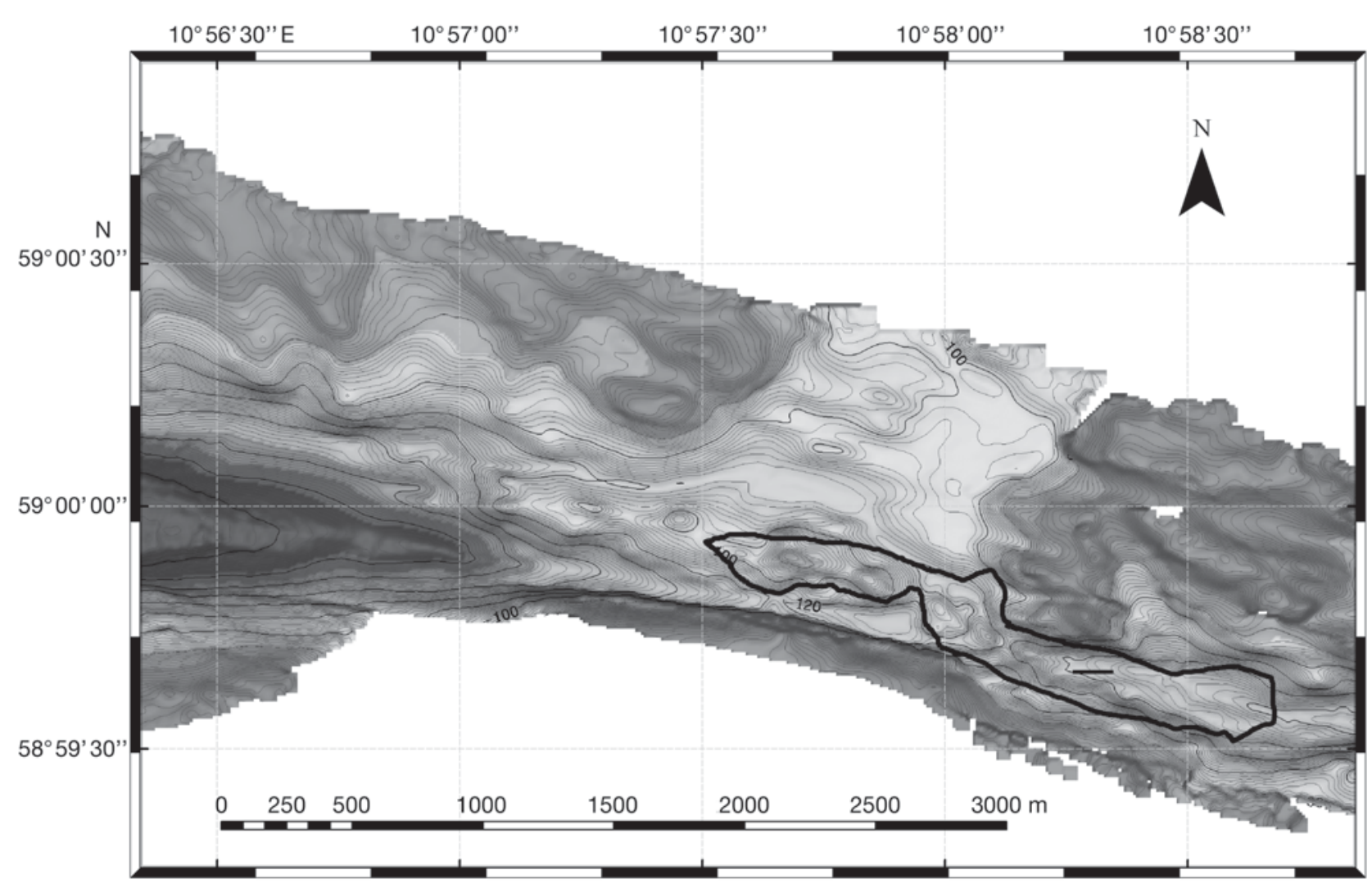

Fig. 1. Location of Tisler Reef and survey transect (black bar). Approximate living reef region is outlined

der (Lundälv 2004). The live proportion covers a region of approximately $1200 \times 200 \mathrm{~m}$ over a depth range of 70 to $160 \mathrm{~m}$. Lophelia pertusa is the significant reef-building coral at the reef.

Video transect data. The video footage was collected by a Sperre SubFighter 7500 DC ROV in October 2007. The transect covered a $\sim 100 \mathrm{~m}$ traverse of the southeast corner of Tisler Reef, with the traverse centred at $58^{\circ} 59.695^{\prime} \mathrm{N}, 10^{\circ} 58.240^{\prime} \mathrm{E}$. Depths ranged from 128 to $145 \mathrm{~m}$. The video footage was collected using a vertically downward-facing WAT-231S camera (Watec) with a Pentax $2.8 \mathrm{~mm}$ wide-angle lens from an altitude of $\sim 2 \mathrm{~m}$. Lighting was provided by 2 downward-facing 200 W hydrargyrum medium-arc iodide lights. The video signals were transmitted over optical fibre and recorded onboard on a DVCAM VTR (Sony). The region covered by the traverse is one that has been subject to considerable trawl activity in the past, such that much of the area is made up of small and moderate-sized living coral boulders and fragments surrounded by areas of coral rubble.

For the analysis, one frame every $2 \mathrm{~s}$ was extracted from the video stream giving a total of 1146 analysis frames from just under $40 \mathrm{~min}$ of film. These frames each covered an area of seabed approximately $2 \times$ $1.5 \mathrm{~m}$ with a resolution of $720 \times 576$ pixels. Since most of the extracted frames showed a degree of illumination vignetting, a border of 30 pixels was removed from all frames prior to analysis, reducing the analysed frame size to $690 \times 546$ pixels. On average, there was a $\sim 70 \%$ overlap between successive frames.

Point quadrat method. To determine percent coverage of an image by the point quadrat method, a grid of points is placed over each image and the species or substrate below each point noted (Guinan et al. 2009). The percent coverage of each species can then be determined. Two grid resolutions of this method were tested: 15-point and 100-point. A simplified list of classification labels was used, with each point assigned as falling on: coralLophelia pertusa, sponge-Geodia baretti, sponge-Mycale lingua or other. A total of 229 analysis frames were assessed for species percent coverage using a 15-point grid overlay. This number represents every 5 th frame extracted from the video stream. Forty-five of the analysis frames were assessed for species percent coverage using the 100-point grid overlay. This number represents every 25th frame extracted. To avoid observer bias, the 15point and 100-point assessments, as well as all other methodologies compared in this pilot study, were carried out by the same biological expert.

Map method. Of the manual analysis methods employed in the present study, the map method was 
the most labour-intensive. For this method, each frame was subdivided into 89 small boxes, and percent coverage of each species and substrate within each of those boxes estimated (Leujak \& Ormond 2007). The total percent coverage for each target species within these 89 boxes was summed and coverage across the whole frame determined. This method was applied to 22 of the analysis frames, every 50th frame extracted.

Auto analysis method. Briefly, this method works by teaching a computer system to identify areas of interest (Lophelia pertusa, Geodia baretti or Mycale lingua) by biological experts labelling a set of training images. From these training images, machine-learning algorithms determine what image texture features and colours represent each of these areas of interest. From this learning process it then attempts to identify such regions in further images uploaded into the system. Fig. 2 shows the architecture of the analysis system. All computation was conducted using a Dell M1530 Intel Core2 Duo processor laptop running at $2.4 \mathrm{GHz}$ running Linux. All 1146 extracted frames were analysed using this method. For the automated detection of corals and sponges the following steps were applied.

Step 1, single-frame extraction: A single frame every $2 \mathrm{~s}$ was extracted from the video stream using a standard video-editing tool. These frames were stored within the Biolmage Indexing, Graphical Labelling and Exploration platform (BIIGLE; Ontrup et al. 2009b). BIIGLE is a rich internet application, which enables users to browse still images with a standard web browser. In addition, BIIGLE allows the user to annotate (label) image regions. A biologist or taxonomist can draw a polygon around an object of interest on the screen and assign the appropriate category name from a list provided. In the present study, a selection of images was labelled, with a total of 250 typical examples of Lophelia pertusa, Geodia baretti and Mycale lingua. These labels formed a training set which was used by the system to automatically detect corals and sponges in images extracted from the same video transect, as discussed in the following steps.

Step 2, computation of numerical features: Underwater video footage is often characterised by variable illumination. It is therefore not always possible to rely on simple image features such as brightness or colour to automatically detect corals and sponges. Additionally, specific shapes or outlines cannot be used because of the variability in growth forms of corals and sponges. As an alternative, a measure was computed based on a small local scale: texture. The computation of numerical texture features is a common topic in image processing literature (for an overview see Mirmehdi et al. 2008). In the present study, 15 differently orientated and spaced gratings were used to produce a set of 30-dimensional texture features for each frame of video. These numerically represent the different optical attributes of corals and sponges with respect to their surface structure. For a detailed description of the approach see Ontrup et al. (2004).

Step 3, machine learning: The numerical data (30dimensional texture features) obtained in the previous step were then fed into the machine-learning component of the auto analysis system. This machine-learning component consists of an artificial neural network and is based on the principle of the so-called self-organizing feature map (SOM) (Kohonen 2001). Generally speaking, a SOM learns to map data similarities from a high-dimensional input space to a lower dimensional map space. In our case, the system learns to map similar texture features to neighbouring regions on a 2dimensional disk space. The algorithm employed within BIIGLE was an extension to the standard SOM termed the hierarchically growing hyperbolic self organizing map ( $\mathrm{H}_{2} \mathrm{SOM}$ ) (Ontrup \& Ritter 2006, Martin et al. 2008, Ontrup et al. 2009a). After training the neural network with the numerical feature vectors, the map partitions the data into hierarchically organized clusters so that image regions with similar optical texture appearances are mapped to the same or neighbouring clusters on the map (shown on the coloured disc in Fig. 2). By mapping the colour of the embedding disk space onto the original still image, a result as shown in Fig. 3 is obtained for each image analysed. This figure shows how the artificial neural network 'sees' the different image regions of the corresponding video still frame.

Step 4, application of expert labels: The previous step outlined how the artificial neural network organizes the numerical feature data. However, to obtain a coverage estimate for each organism for each image, a further step is required: attachment of a 2-dimensional vector to each node of the network. The first component counts how many image patches the node contains which have been labelled as Lophelia pertusa. The second component counts the number of labels for either of the sponges Mycale lingua or Geodia baretti. Therefore, each node of the $\mathrm{H}_{2} \mathrm{SOM}$ carries a label, which is directly taken from the expert labels of the training set (Step 1). Note that the network produced in Step 3 is built in an unsupervised fashion. This means that the training process itself does not depend on human labels. The system organizes all video frames and uses the training set frames to 'learn' from the human. By mapping the range of the 2-dimensional label vectors to the red and green channels of an RGB image, a coloured categorised image is obtained (Fig. 3). The red areas of the image are those recognised by the system as being covered by coral, and the green areas those covered by sponges. In the present study, to determine the percent coverage estimates for 


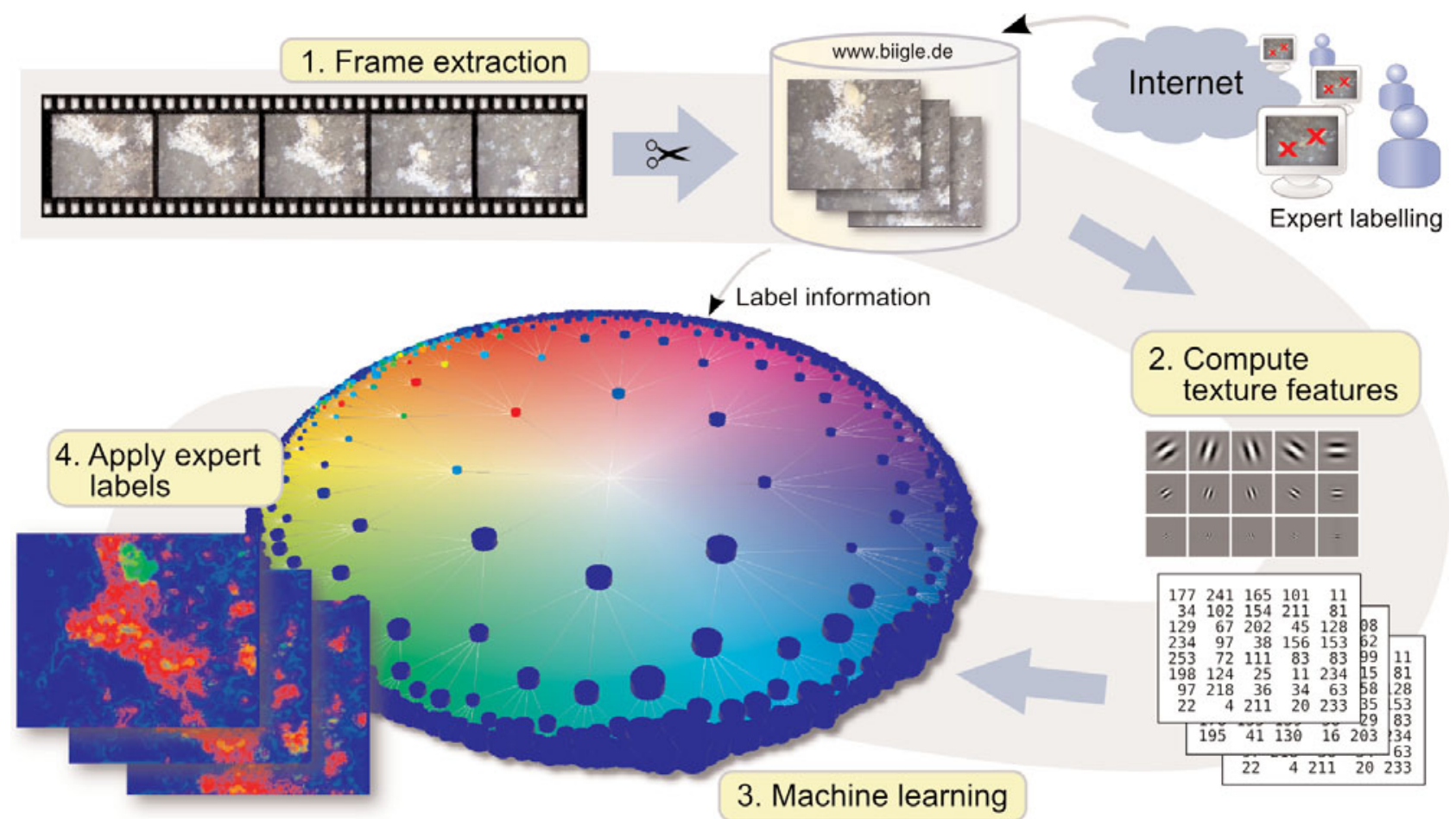

Fig. 2. Architecture of the auto analysis system. The wide arrows indicate the processing path corresponding to the 4 steps as described in the 'Materials and methods'. The central part of the figure shows the artificial neural network visualised as the coloured disk. This separates the video data into hierarchically organized clusters shown as small circles on the map space
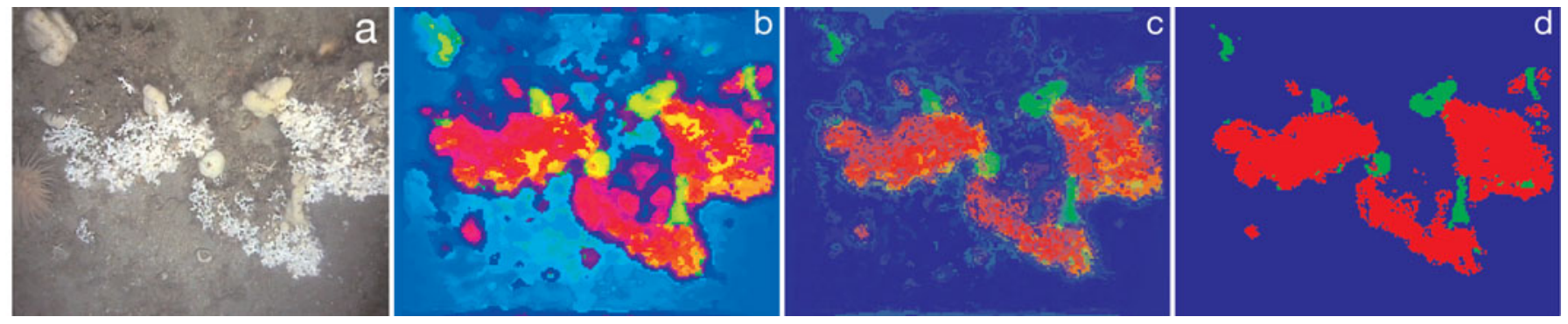

Fig. 3. Sequence of result images from the auto analysis processing pipeline. (a) The original video frame. (b) The cluster colours the neural network has learned from the texture data. Note that this image is generated without any expert labels (unsupervised training process only). For preparation of (c), expert labels were applied to the neural network. Depending on the number of coral or sponge labels within the clusters on the map, regions of the image are coloured red or green, respectively. (d) The final categorised frame from which the coverage estimations are produced by counting the coloured pixels

these organisms within each frame, the number of red and green pixels within each of these colour coded classification frames was computed. By dividing these pixel counts by the total number of pixels in each frame, percent cover was determined. These percent coverage results from each frame were written to a database for further evaluation. Additionally, these colour-categorised images were assembled into a categorised video, which was played alongside the raw transect video footage. Running these categorised videos alongside the raw video enabled a rapid assessment of how well the auto analysis system deals with artifacts such as variable illumination and heave. The raw video and categorised video produced in the present study are available for viewing as online supplementary material at: www.int-res.com/articles/suppl/ m397p241_app/.

Determination of assessment effort. Since all the methods used in the present study utilised the same video data, the sampling effort for each was the same. However, the analysis time varied greatly with method. The time spent on each stage of analysis was measured and an average time expenditure per frame determined. 
Data analysis. The percent cover estimations obtained by each of the various methods can be regarded as a time-series where, for each video frame (point in time), a measurement (coverage estimation for each fauna type) is taken. To assess the quality of the auto analysis method, a statistical measure to compare its results with the results produced by the human expert using the other tested methodologies was required. A common way to achieve such a comparison is by means of a crosscorrelation analysis (Box \& Jenkins 1994). Such a crosscorrelation measures the degree of correlation between 2 time-series with respect to their time lag, i.e. how the first series correlates to the second if the measurements are compared at time points taken $x$ samples apart, where $x$ is the time lag. In this case, the largest correlation between 2 methods at a time lag of zero would be expected if the 2 sets of results correlate well - a crosscorrelation score of 1 indicates perfect correlation. Additionally, $99 \%$ confidence intervals were determined for the cross-correlation scores. Where the $99 \%$ confidence interval was found to be lower than the cross-correlation score, the null-hypothesis that the 2 data sets were not correlated could be rejected with high confidence. Aside from identifying broad statistical differences in the success of the various methodologies in quantifying Lophelia pertusa and sponge coverage across the transect as a whole, methodologies were compared on a frame-by-frame basis (bar charts show percent coverage estimations by method for each frame analysed).

\section{RESULTS}

\section{Lophelia pertusa coverage estimations}

Cross correlation between all methodologies and the map method showed significant positive correlations (Table 1). Auto analysis/map had a correlation coefficient only 0.075 lower than the 15-point/ map correlation coefficient, indicating that Lophelia pertusa coverage estimations made by the auto analysis and 15-point methods correlate similarly with changes in map estimations. The more labourintensive 100-point method had the strongest positive correlation with the map method, with a coefficient of 0.981. Both the auto analysis and 15-point methods produced enough data to plot a continuous time-series for the distribution of $L$. pertusa across the whole transect. Figs. 4 \& 5 show
Table 1. Results of cross-correlation comparisons between the various tested methodologies in identification of Lophelia pertusa and the sponges Geodia baretti and Mycale lingua

\begin{tabular}{|lccc|}
\hline Test & $\begin{array}{c}\text { No. } \\
\text { frames }\end{array}$ & $\begin{array}{c}\text { Cross- } \\
\text { correlation }\end{array}$ & $\begin{array}{c}99 \% \\
\text { confidence } \\
\text { interval }\end{array}$ \\
\hline $\begin{array}{l}\text { Lophelia pertusa } \\
\text { identification }\end{array}$ & & & \\
Auto analysis/15-point & 229 & 0.791 & 0.172 \\
Auto analysis/100-point & 45 & 0.794 & 0.382 \\
Auto analysis/Map & 22 & 0.869 & 0.571 \\
15-point/100-point & 45 & 0.862 & 0.394 \\
15-point/Map & 22 & 0.944 & 0.543 \\
100-point/Map & 22 & 0.981 & 0.552 \\
Sponge identification & & & \\
Auto analysis/15-point & 229 & 0.482 & 0.130 \\
Auto analysis/100-point & 44 & 0.531 & 0.292 \\
Auto analysis/Map & 22 & 0.520 & 0.548 \\
15-point/100-point & 44 & 0.794 & 0.293 \\
15-point/Map & 22 & 0.867 & 0.551 \\
100-point/Map & 22 & 0.971 & 0.547 \\
\hline
\end{tabular}

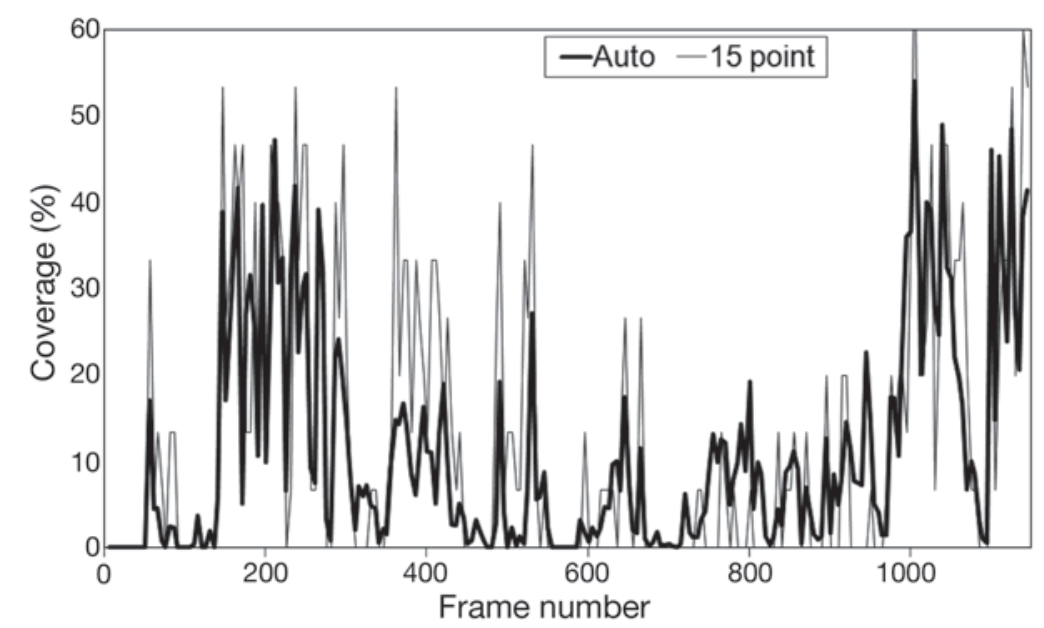

Fig. 4. Lophelia pertusa. Comparison between L. pertusa percent coverage estimates from transect data produced by the auto analysis and 15-point methods

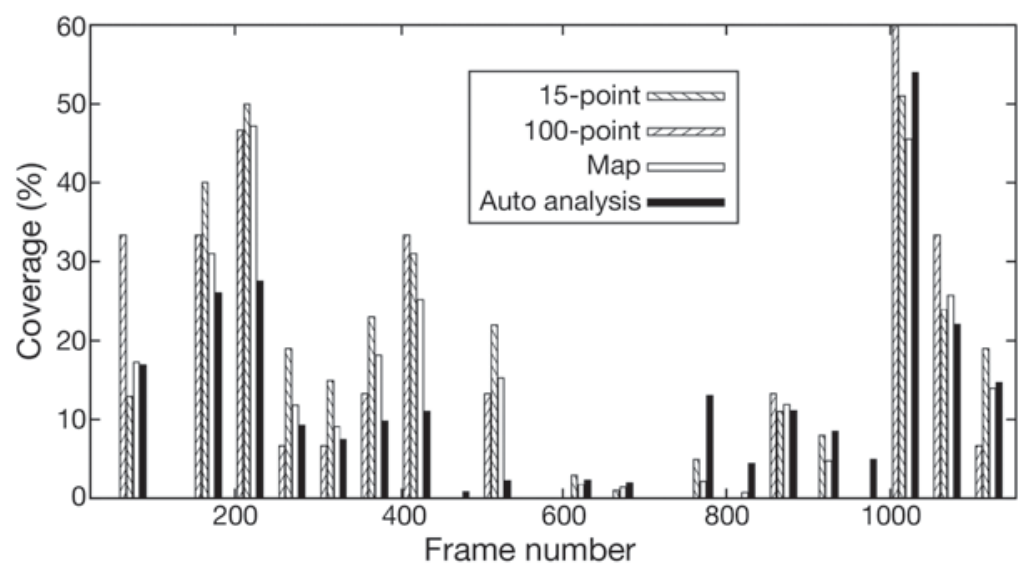

Fig. 5. Lophelia pertusa. Comparison of different methods for the determination of $L$. pertusa percent coverage 
the distributions of $L$. pertusa across the transect given by the various methodologies. The rapid 15-point assessment method and auto analysis method were comparable in identifying regions of $L$. pertusa, but the percent coverage estimations made by auto analysis was generally a few percent lower than those made by the 15-point method (Fig. 4). There were several maxima in the 15-point method data which were not picked up by auto analysis, particularly in the area between Frames 350 and 525. An example of such an underestimation by the auto analysis method is shown in Fig. 6, which shows that the system has not identified some areas of $L$. pertusa toward the top and left of Frame 406. There was strong similarity between the 100-point and the map method estimations, as would be expected from the strong correlation coefficient (Fig. 5, Table 1). Additionally, there was reasonable similarity between estimations produced by the 15-point and map methods; however, the 15-point method is not suited to detecting coral presence in images of regions where coral coverage is low $(\sim<5 \%$ Fig. 5). Auto analysis, however, appears to locate small, isolated coral fragments in such images more successfully than the 15-point method (Frames 575 to 700 , Fig. 5). The auto analysis/map comparison indicated only one small overestimation of $L$. pertusa by the auto analysis system (Frame 756, Fig. 7). Here the system had mistaken a sponge (Geodia baretti) covered with small sediment-filled pockets or holes for L. pertusa. Comparisons between the auto analysis and 100-point methods (Fig. 5) show similar coverage estimations for the majority of the transect, with 2 small overestimations by the auto analysis method between Frames 600 and 800 and a few underestimations of between 5 and $20 \%$ at various points of the transect.

\section{Sponge coverage estimations}

Strong positive correlations between the map method and both the 15-point and 100-point methods were found (Fig. 8). The strengths of correlations for each method match almost exactly those produced by each comparable correlation in Lophelia pertusa percent cover estimation. Although still positive, the auto analysis/map correlation coefficient was statistically weaker, at 0.504 .

Estimation of sponge coverage across the transect varied significantly with methodology. The 15-point method produced numerous sponge density peaks that were more muted or completely absent from the auto analysis results (Fig. 9). Throughout the whole transect, the auto analysis method estimated a sponge coverage of $\sim 0.5$ to $2.5 \%$ in most frames, although this low 'background' sponge coverage estimation was completely absent from the 15-point results.

Fig. 8 shows for comparison the sponge coverage estimations produced by the various methodologies across the transect. There was generally a poor correlation between both the auto analysis and 15-point methods with the map method in estimating sponge coverage. The 100-point method correlated reasonably well with the map method.

\section{Assessment effort}

Table 2 shows a breakdown of the time required by each method for coral and sponge coverage analysis. For the auto analysis method, the time taken to process each image inclusive and exclusive of the time taken for the biological expert to enter labels identifying coral and sponge areas onto the training frames within the BIIGLE system was also shown. The rationale behind this is to show that once this manual, labourintensive task is done, the computing time to produce the auto analysis result for each frame is minimal. In the $\sim 17 \mathrm{~h}$ spent analyzing 22 frames with the map method, the auto analysis method analysed $\sim 50$ times this number, i.e. 1146 frames.

\section{DISCUSSION}

\section{Auto analysis approach: strengths and weaknesses}

The automated system allows a much greater volume of image data to be assessed in a particular timeframe than would be possible with any of the other methodologies discussed in the present study. Although the time taken to set up the auto analysis system is greater 

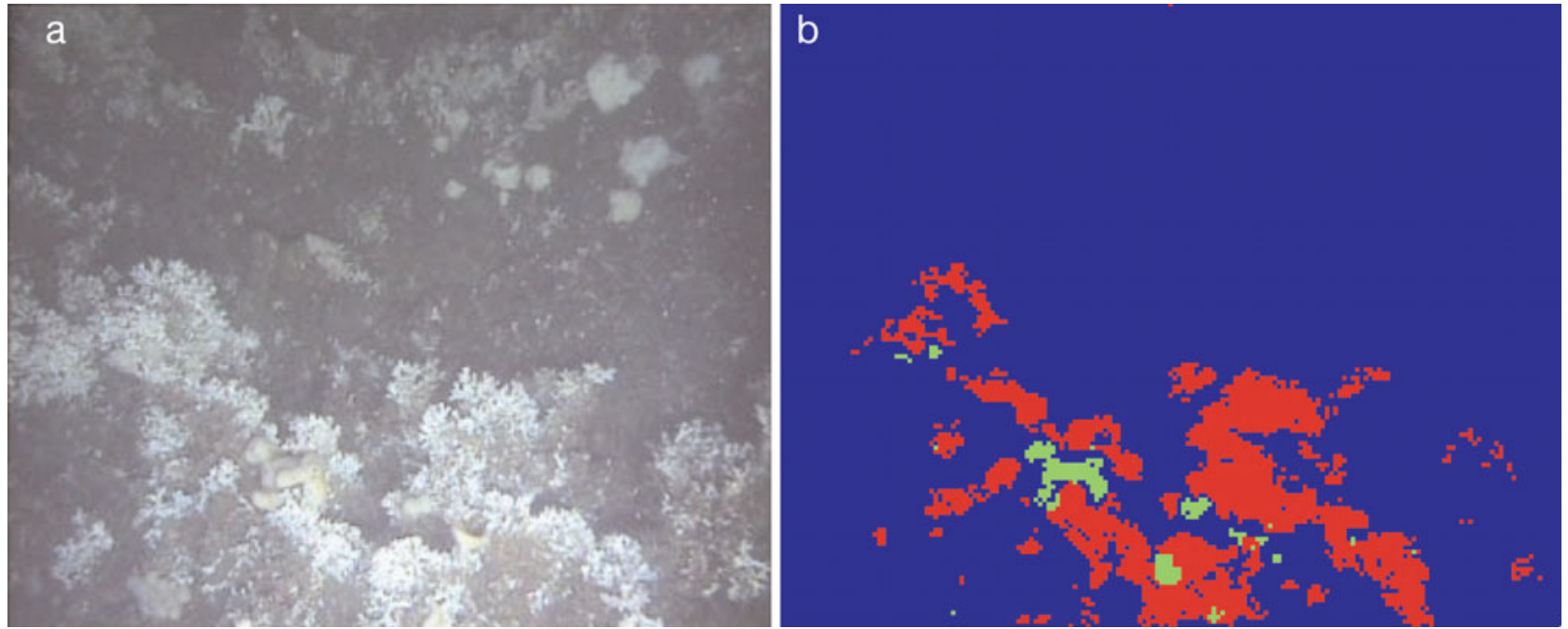

Fig. 6. Lophelia pertusa. Frame 406. (a) Raw video frame and (b) auto analysis of L. pertusa regions (red). The more distant $L$. pertusa seen at the top and to the extreme left side in (a) are not identified as L. pertusa by the system. The distant sponges are likewise missed
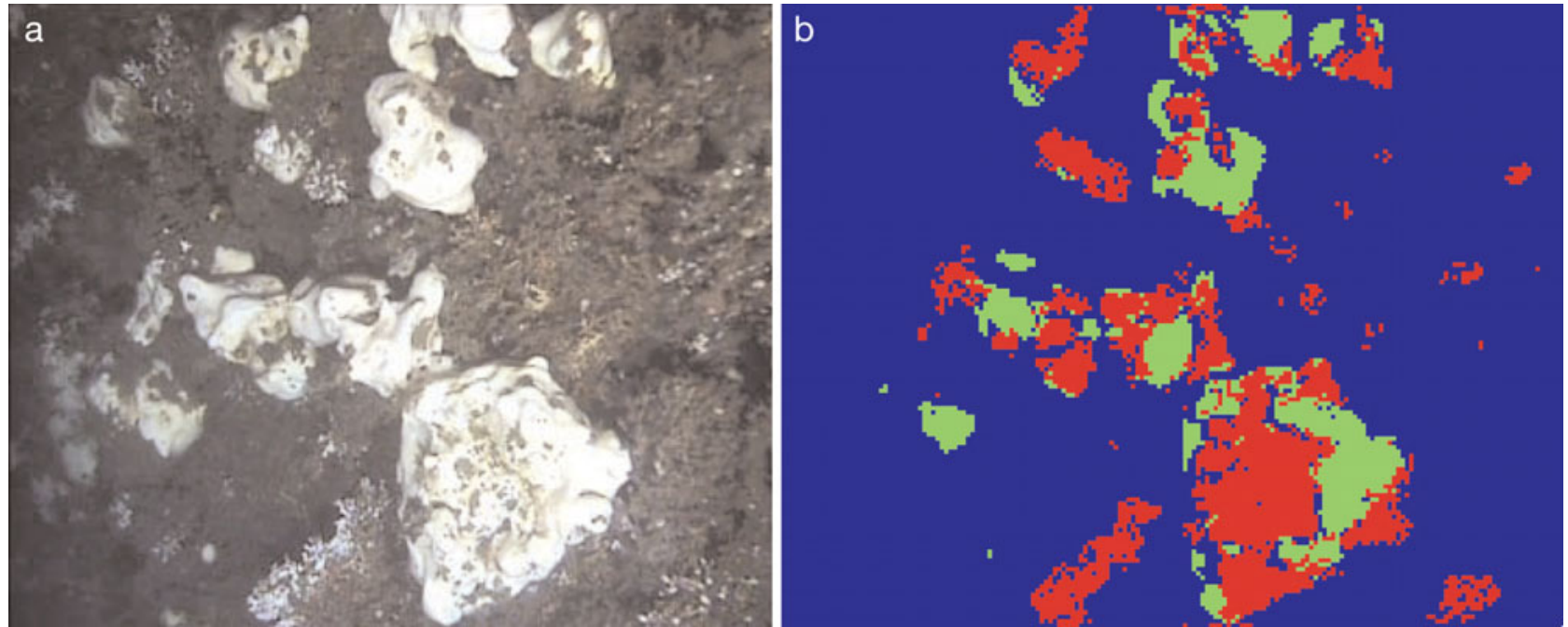

Fig. 7. Lophelia pertusa. Frame 756. (a) Raw video frame and (b) auto analysis of L. pertusa regions (red). The system has identified a region of $L$. pertusa in the foreground correctly, but it has mistakenly identified parts of a couple of 'dirty' Geodia baretti sponges also as being $L$. pertusa

(Table 2), once the setup is completed, a large number of frames can be processed rapidly without manual intervention. This is a significant strength of the system. With current marine imaging techniques, large quantities of images can be rapidly collected, but visual analysis - even by the 15-point method - becomes a timeconsuming and labour-intensive task.

The auto analysis approach produced Lophelia pertusa coverage estimates very similar to those produced by the 15-point method, and in images containing sparse coral coverage consisting of a few isolated fragments (such as can be found across areas of Tisler Reef), the auto analysis method outperformed the 15- point method. The unsuitability of the point method in identifying small, rare features has been previously observed, particularly when a low number of grid points is used (Dethier et al. 1993).

Although the auto analysis method appears to be a more suitable method to detect small patches of live coral amongst coral rubble than the 15-point method, it does appear to underestimate coral coverage slightly in regions where coral is abundant. An example of such an underestimation is shown in Fig. 6, where the auto analysis appears to underestimate coral coverage in regions where coral is abundant, particularly where lighting intensity is variable. There are 2 ways such 


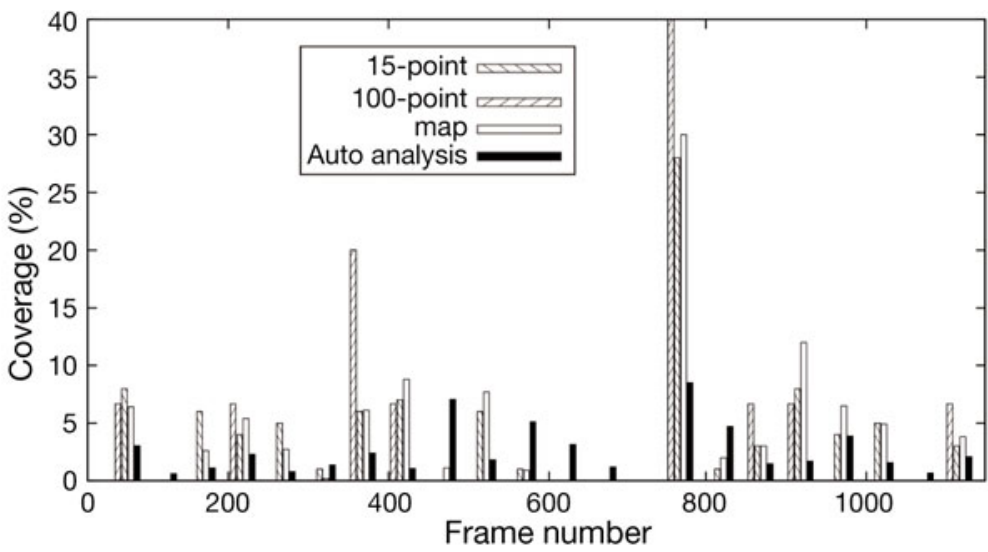

Fig. 8. Geodia baretti and Mycale lingua. Comparison of different methods for the determination of sponge percent coverage

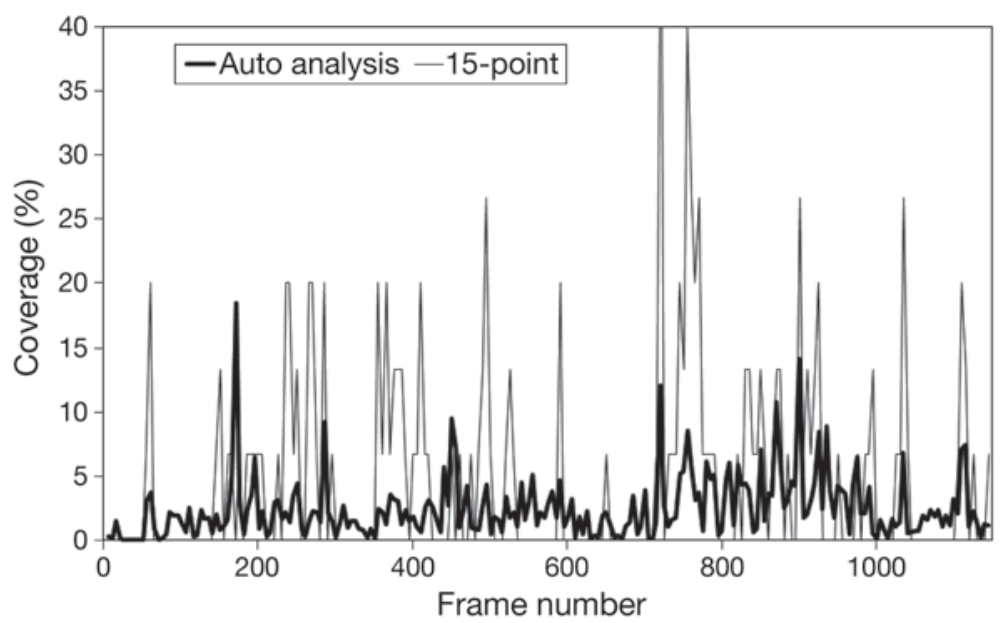

Fig. 9. Geodia baretti and Mycale lingua. Comparison between sponge percent coverage estimates from transect data produced by the auto analysis and 15-point methods

illumination problems could be addressed in future analyses. (1) The images labelled by experts in Step 1 of the auto analysis procedure could be modified. Additional label categories (e.g. L. pertusa-strong illumination, L. pertusa-poor illumination) could be used by the labelling experts. After auto analysis, these 2 categories could be summed to produce the total estimated $L$. pertusa coverage for each frame. This approach may have a limited success in the improvement of coverage estimations. The low light levels in the poorly illuminated frame regions, however, remove many of the texture features from the image required by the system (and to an extent by the human eye) to differentiate successfully between the 2 sponge species and L. pertusa. (2) Scan through the frames imported into the auto analysis system in advance of processing, and remove frames where there is seen to be considerable variation in illumination. This second option would increase the required processing time. Overestimations in L. pertusa coverage were not a common problem with the auto analysis method, but for the few frames where overestimations did occur, they could be attributable to either the extreme illumination of coral rubble associated with the ROV passing in very close proximity to the seabed or the misidentification of sponge regions as $L$. pertusa. The first source of error can be guarded against by viewing the raw data video alongside the auto analysis categorised video and marking down frames of concern. The misidentification of sponge regions could be addressed by increasing the range of sponge morphologies represented in the training set produced during Step 1 of the auto analysis process.

The auto analysis method had limited success in sponge coverage quantification. The great variation in texture and colouration of sponges from Tisler Reef may have affected the ability of the system to accurately quantify coverage. The present study also shows the 15-point method to be of little use in accurately assessing sponge coverage of the seabed in the Tisler Reef area. An increased number of labelled sponges in the training set (Step 1) may have helped the auto analysis system identify more sponges in the images and reduce misidentification of regions of the seabed as sponge (background sponge coverage estimate of $\sim 0.5$ to $2.5 \%$, Fig. 9).

In the present study, we did not look at the applicability of the auto analysis system for distinguishing substrate type or species other than Lophelia pertusa, Geodia baretti and Mycale lingua. The auto analysis system can be trained to identify substrates or further species if a sufficient number of training labels are provided by experts. Initial auto analysis trials using earlier algorithms for the enumeration of soft-sediment biota from the deep-sea longterm observatory HAUSGARTEN indicate an identification accuracy of 86 and $75 \%$ for sea cucumbers (Elpididae) and starfish Bathybiaster vexillifer, respectively (Ontrup et al. 2009a).

\section{Applicability for reef-mapping}

A great advantage of the auto analysis method is the production of the categorised frames for each image imported into the system (Figs. $6 \& 7$ ). Each of these categorised frames can be regarded as a small- 
scale coral and sponge distribution map. Provided the initial video is collected with accurate positioning data, these images can readily be imported into standard GIS software and used as overlays of video mosaic maps produced from the raw frames. A further option would be to import the auto analysis categorised frames into GIS bathymetry maps. This potential application is not offered by any of the other methods tested here except for the time-consuming map method.

\section{Applicability for management and monitoring}

Monitoring the success of fishery closures of coldwater coral areas can be costly in both time and finances (Morgan et al. 2005). European states fit registered fishing vessels with vessel monitoring systems (VMS), which regularly declare their position via satellite (Deng et al. 2005). The activities of vessels not fitted with VMS are harder to ascertain, particularly offshore. Further damage following closures can only be assessed satisfactorily by visual inspection of the reefs, and by comparing these inspections with those made previously. The auto analysis method presented in the present study could potentially be used to record and quantify Lophelia pertusa coverage along selected transects at protected reefs and/or those at risk. Depending on local conditions, the auto analysis system may not require re-training between ROV surveys. The high success rate of the system at identifying the small, live fragments of $L$. pertusa amongst coral rubble could be a particularly useful feature for surveys of damaged and at risk reefs such as Tisler Reef, with such fragments being possible indicators of trawl activity (Hall-Spencer et al. 2002, Reed et al. 2007). The distribution and percent coverage of these living fragments in the coral rubble area surrounding the living Tisler Reef edge could be readily monitored over time with this auto analysis system. Any local increase in percent coverage by such fragments or large-scale rearrangements of fragments between surveys could be indicative of ongoing fishing activity.

Acknowledgements. This project was funded by StatoilHydro and the FP6 EU-project HERMES (EC contract no. GOCE-CT2005-511234) and is a CORAMM group collaboration. J. M. Hall-Spencer, A. Larsson, L. Jonsson and A. Davies kindly labelled fauna in BIIGLE. L. Jonsson additionally assisted with collection of video footage. B. Lessmann set up early stages of the automated image analysis system. N. Ehnert and T. Schoening helped to set up BIIGLE. A.P. acknowledges the support of his PhD supervisor L. Thomsen in the preparation of this paper. We also thank the 4 anonymous reviewers for their valuable comments which were of great help in improving this paper. This paper is publication awi-n17768 of the Alfred Wegener Institute for Polar and Marine Research.

\section{LITERATURE CITED}

Andrew NL, Mapstone BD (1987) Sampling and the description of spatial pattern in marine ecology. Oceanogr Mar Biol Annu Rev 25:39-90

Armstrong CW, van den Hove S (2008) The formation of policy for protection of cold-water coral off the coast of Norway. Mar Policy 32:66-73

Box G, Jenkins G (1994). Time series analysis: forecasting and control. 3rd edn. Prentice Hall, Englewood Cliffs, NJ

Costello M, McCrea M, Freiwald A, Lundälv T and others (2005) Role of cold-water Lophelia pertusa coral reefs as fish habitat in the NE Atlantic. In: Friewald A, Roberts JM (eds) Cold-water corals and ecosystems. Springer, Berlin, p 771-805

> Davies AJ, Roberts JM, Hall-Spencer J (2007) Preserving deep-sea natural heritage: emerging issues in offshore conservation and management. Biol Conserv 138:299-312

De Mol B, Kozachenko M, Wheeler A, Alvares H, Henriet JP, Roy KOL (2007) Therese Mound: a case study of coral bank development in the Belgica Mound Province, Porcupine Seabight. Int J Earth Sci 96:103-120

> Deng R, Dichmont C, Milton D, Haywood M, Vance D, Hall N, Die D (2005) Can vessel monitoring system data also be used to study trawling intensity and population depletion? The example of Australia's northern prawn fishery. Can J Fish Aquat Sci 62:611-622

Dethier M, Graham E, Cohen S, Tear LM (1993) Visual versus random-point percent cover estimations: 'objective' is not always better. Mar Ecol Prog Ser 96:93-100

Dorschel B, Hebbeln D, Foubert A, White M, Wheeler AJ (2007) Hydrodynamics and cold-water coral facies distribution related to recent sedimentary processes at Galway Mound west of Ireland. Mar Geol 244:184-195

Fosså JH, Mortensen PB, Furevik DM (2002) The deep-water coral Lophelia pertusa in Norwegian waters: distribution and fishery impacts. Hydrobiologia 471:1-12

Fosså J, Lindberg B, Christensen O, Lundälv T, Svellingen I, Mortensen P, Alvsvåg J (2005) Mapping of Lophelia reefs in Norway: experiences and survey methods. In: Friewald A, Roberts JM (eds) Cold-water corals and ecosystems. Springer, Berlin, p 359-391

Foster MS, Harrold C, Hardin DD (1991) Point vs. photo quadrat estimates of the cover of sessile marine organisms. J Exp Mar Biol Ecol 146:193-203

> Gass SE, Roberts JM (2006) The occurrence of the cold-water coral Lophelia pertusa (Scleractinia) on oil and gas platforms in the North Sea: colony growth, recruitment and environmental controls on distribution. Mar Pollut Bull 52: 549-559

Guinan J, Grehan AJ, Dolan MFJ, Brown C (2009) Quantifying relationships between video observations of coldwater coral cover and seafloor features in Rockall Trough, west of Ireland. Mar Ecol Prog Ser 375:125-138

> Hall-Spencer J, Allain V, Fosså JH (2002) Trawling damage to Northeast Atlantic ancient coral reefs. Proc R Soc Lond B Biol Sci 269:507-511

Henry LA, Roberts JM (2007) Biodiversity and ecological composition of macrobenthos on cold-water coral mounds and adjacent off-mound habitat in the bathyal Porcupine Seabight, NE Atlantic. Deep-Sea Res I 54: $654-672$

Hovland M (2008) Deep-water coral reefs: unique biodiversity hotspots. Springer, Berlin

- Husebø Å, Nøttestad L, Fosså JH, Furevik DM, Jørgensen SB (2002) Distribution and abundance of fish in deep-sea coral habitats. Hydrobiologia 471:91-99 
Jaap WC, Mc Field MD (2001) Video sampling for monitoring coral reef benthos. Bull Biol Soc Wash 10:269-273

Jonsson L (2006) Ecology of three coastal cold-water cnidarians, in particular the scleractinian Lophelia pertusa. PhD dissertation, University of Gothenburg

> Jonsson LG, Nilsson PG, Floruta F, Lundälv T (2004) Distributional patterns of macro- and megafauna associated with a reef of the cold-water coral Lophelia pertusa on the Swedish west coast. Mar Ecol Prog Ser 284:163-171

Kiriakoulakis K, Freiwald A, Fisher E, Wolff GA (2007) Organic matter quality and supply to deep-water coral/ mound systems of the NW European Continental Margin. Int J Earth Sci 96:159-170

Kohonen T (2001) Self-organizing maps, 3rd edn. Springer, Berlin

Lavaleye M, Duineveld G, Lundälv T, White M, Guihen D, Kiriakoulakis K, Wolff GA (2009) Cold-water corals on the Tisler Reef: preliminary observations on the dynamic reef environment. Oceanography 22:54-62

Leujak W, Ormond RFG (2007) Comparative accuracy and efficiency of six coral community survey methods. J Exp Mar Biol Ecol 351:168-187

Lundälv T (2004) Kartläggning av marina habitat i Yttre Hvaler, nordöstra Skagerrak. En pilotstudie. I. Kartlegging av marine naturtyper. En nordisk pilotstudie. Nordic Council of Ministers, Copenhagen, p 30-39

Lundälv T, Jonsson L (2003) Mapping of deep-water corals and fishery impacts in the NE Skagerrak, using acousticaland ROV survey techniques. Proc 6th Underwater Sci Symp, Aberdeen (Abstract)

Martin C, Diaz N, Ontrup J, Nattkemper TW (2008) Hyperbolic SOM-based clustering of DNA fragment features for taxonomic visualization and classification. Bioinformatics 24:1568-1574

Mirmehdi M, Xie XH, Suri J (2008) Handbook of texture analysis. Imperial College Press, London

Morgan L, Etnoyer P, Scholz A, Mertens M, Powell M (2005) Conservation and management implications of deepsea coral and fishing effort distributions in the Northeast Pacific Ocean. In: Friewald A, Roberts JM (eds) Cold-water corals and ecosystems. Springer, Berlin, p 1171-1187

Mortensen PB, Buhl-Mortensen L, Gebruk AV, Krylova EM (2008) Occurrence of deep-water corals on the MidAtlantic Ridge based on MAR-ECO data. Deep-Sea Res II 55:142-152

Ontrup J, Ritter H (2006) Large-scale data exploration with the hierarchically growing hyperbolic SOM. Neural Netw 19:751-761

Ontrup J, Wersing H, Ritter H (2004) A computational feature binding model of human texture perception. Cogn Process 5:31-44

Ontrup J, Ehnert N, Schöning T, Bermann M, Nattkemper TW (2009a) BIIGLE - Web 2.0 enabled labelling and exploring of images from the Arctic deep-sea observatory HAUSGARTEN. Proc OCEANS'09, IEEE, Bremen

Ontrup J, Ritter H, Scholz SW, Wagner R (2009b) Detecting, assessing and monitoring relevant topics in virtual infor-

Submitted: March 2, 2009; Accepted: June 8, 2009 mation environments. IEEE Trans Knowledge Data Eng 21:415-427

Orejas C, Gori A, Gili JM (2008) Growth rates of live Lophelia pertusa and Madrepora oculata from the Mediterranean Sea maintained in aquaria. Coral Reefs 27:255

Pielou EC (1974) Population and community ecology: principles and methods. Gordon \& Breach, New York

Reed JK (2002) Deep-water Oculina coral reefs of Florida: biology, impacts, and management. Hydrobiologia 471: $43-55$

Reed JK, Koenig CC, Shepard AN (2007) Impacts of bottom trawling on a deep-water Oculina coral ecosystem off Florida. Bull Mar Sci 81:481-496

> Roberts JM, Long D, Wilson JB, Mortensen PB, Gage JD (2003) The cold-water coral Lophelia pertusa (Scleractinia) and enigmatic seabed mounds along the north-east Atlantic margin: Are they related? Mar Pollut Bull 46:7-20

Roberts JM, Brown CJ, Long D, Bates CR (2005) Acoustic mapping using a multibeam echosounder reveals coldwater coral reefs and surrounding habitats. Coral Reefs 24:654-669

> Roberts JM, Wheeler AJ, Freiwald A (2006) Reefs of the deep: the biology and geology of cold-water coral ecosystems. Science 312:543-547

Roberts JM, Henry LA, Long D, Hartley JP (2008) Cold-water coral reef frameworks, megafaunal communities and evidence for coral carbonate mounds on the Hatton Bank, north east Atlantic. Facies 54:297-316

Rogers AD (1999) The biology of Lophelia pertusa (LINNAEUS 1758) and other deep-water reef-forming corals and impacts from human activities. Int Rev Hydrobiol 84:315-406

Thiem O, Ravagnan E, Fossa JH, Berntsen J (2006) Food supply mechanisms for cold-water corals along a continental shelf edge. J Mar Syst 60:207-219

Wheeler AJ, Beyer A, Freiwald A, de Haas $\mathrm{H}$ and others (2007) Morphology and environment of cold-water coral carbonate mounds on the NW European margin. Int J Earth Sci 96:37-56

White M, Mohn C, Stigter H, Mottram G (2005) Deep-water coral development as a function of hydrodynamics and surface productivity around the submarine banks of the Rockall Trough, NE Atlantic. In: Friewald A, Roberts JM (eds) Cold-water corals and ecosystems. Springer, Berlin, p 503-514

Whorff JS, Griffing L (1992) A video recording and analysis system used to sample intertidal communities. J Exp Mar Biol Ecol 160:1-12

> Wienberg C, Beuck L, Heidkamp S, Hebbeln D, Freiwald A, Pfannkuche O, Monteys X (2008) Franken Mound: facies and biocoenoses on a newly-discovered 'carbonate mound' on the western Rockall Bank, NE Atlantic. Facies $54: 1-24$

Wisshak M, Freiwald A, Lundälv T, Gektidis M (2005) The physical niche of the bathyal Lophelia pertusa in a nonbathyal setting: environmental controls and palaeoecological implications. In: Friewald A, Roberts JM (eds) Cold-water corals and ecosystems. Springer, Berlin, p 979-1001

Proofs received from author(s): October 1, 2009 